\title{
AWAM: a model for optimal land and water resources allocation
}

\author{
I. Smout ${ }^{1} \&$ S. D. Gorantiwar ${ }^{1,2}$ \\ ${ }^{1}$ WEDC, Department of Civil and Building Engineering, \\ Loughborough University, $U K$ \\ ${ }^{2}$ Department of Irrigation and Drainage Engineering, \\ M. P. Agricultural University, Rahuri, India
}

\begin{abstract}
Planning for irrigation water management in rotational irrigation schemes consists of the preparation of an allocation plan for distribution of land and water resources to different crops up to tertiary or farm level, and water delivery schedules in terms of timing and amount of water delivery for this allocation plan according to the set objectives/targets. It is necessary to consider the heterogeneity in soils and climate, and complexity of the water distribution network, while developing these allocation plans. Further, there is a need to allocate water both efficiently and equitably. The preparation of the allocation plan becomes a complex process when the water availability is less than the demand for water for adequate irrigation of the culturable command area of the irrigation scheme. In the past, several methodologies have been developed to prepare the allocation plans during the planning process. However these models do not consider the above mentioned requirements together. This paper presents the developed model, AWAM (Area and Water Allocation Model) that addresses the heterogeneity in the irrigation scheme and includes the performance measures of productivity and equity while developing the allocation plans. The AWAM model has four phases to be executed separately for each set of irrigation interval over the irrigation season. The paper briefly discusses the applicability of the AWAM model by producing land and water allocation plans and water delivery schedules for case study of the Nazare medium irrigation scheme in Southern India.
\end{abstract}

Keywords: optimization, irrigation, land \& water allocation, productivity, equity. 


\section{Introduction}

The irrigation schemes in semi-arid and arid regions operate under rotational water distribution. These schemes are usually large and heterogeneous in nature i.e. with several crops, soils and a large network of canals with varying characteristics. Spreading water over a large area has been a strategy of irrigation in these irrigation schemes, mainly to provide protective irrigation and alleviate famine. As a result of this, water is shorter in supply than land and most cultivable command areas do not get enough water (adequate irrigation depth). Hence the irrigation management in such cases is a complex process. It requires decisions on how much water and area should be allocated to different crops when grown on different soils and in different parts or regions of the scheme (the allocation plan), based on water availability, maximization of benefits, equitable water supply, different needs and physical constraints of the scheme. Similarly releasing the appropriate quantity of water at the appropriate time to the different crops in different fields from the reservoir headwork through the canal system (the water release schedule) is also important for the maximum benefits. Hence it is important to identify the optimum allocation plan and corresponding water release schedule for the canal network.

Previous research by the authors [1, 2], identified three possible modelling approaches depending on the water availability in the schemes, based on which decisions can be made regarding the allocation of land and water to different crops and the schedule of operation of the canal system. The first is when the water supply in the scheme is adequate; the second is when the water supply is limited but the cropping pattern (or areas) is pre-decided and the third case is when the water supply is limited and the cropping pattern (or areas) can be chosen freely. The approach adopted in the third category of models is appropriate as the area and water resources are allocated optimally to different crops without assuming the allocation policy for any of the resources as known. This is done by considering several alternative levels of crop water requirement and the corresponding yield over the entire season or over an individual irrigation period.

Analysis based on the entire season considers the optimum distribution of the seasonal irrigation depth over different irrigation periods of the crop season separately for each crop. Therefore, these models may not give the appropriate optimum solution in a multicrop situation. In contrast, analysis based on the individual irrigation period makes use of several combinations of irrigation depth per irrigation application and the corresponding crop yield for each crop. It is therefore most appropriate in a multicrop and water-limiting situation and has been adopted by various researchers [3-5]. However all these models are solved at one level i.e. allocating the resources available at tertiary level to tertiary level or allocating the resources available at scheme level to scheme level (the single field type of model). This makes it difficult to apply the allocation results to the operation of the scheme because these do not specify the spatial distribution of the allocated resources. 
In addition, these studies were mainly concerned with maximizing the benefits of agricultural production from the irrigation schemes (i.e. productivity) and did not address the issues of distributing the water to farmers in different parts of the command area of irrigation schemes, in particular whether farmers get an equitable share of water (i.e. equity).

Hence the problem needs to be solved differently. In the present paper, a resource optimization model (Area and Water Allocation Model, AWAM) is presented for rotational irrigation systems where shortages of water prevent adequate irrigation of the whole irrigable command area of the irrigation scheme. This model optimally allocates the area and water to different crops grown in different regions of the irrigation scheme while considering the equity in distribution of resources such as water or irrigated area or output such as crop production or net benefits.

\section{AWAM Model}

The AWAM model [1,2] (fig. 1) allocates the land area and available surface water to different crops cultivated in different parts of the irrigation scheme to maximize the net benefits from the irrigation and is developed for the irrigation schemes which operate under rotational water supply. The model is designed for allocating the resources available at scheme level to the tertiary level and for deciding the water release schedule at tertiary level. The irrigation interval is assumed to be pre-determined and uniform for all crop and soil combinations. AWAM model has the following four phases and is executed for each irrigation interval or a set of irrigation intervals over the irrigation season or year.

\section{Generation of irrigation strategies}

3. Selection of irrigation programmes
2. Preparation of irrigation programmes

4. Optimum allocation of resources

\subsection{Phases of AWAM model}

\subsubsection{Generation of irrigation strategies}

The area of an irrigation scheme with similar climate (Region), soil (Soil group) and crop is termed as Crop-Soil-Region (CSR) unit (but this is not a physical division of the irrigation scheme). As stated earlier, water scarcity in these schemes may make deficit irrigation more profitable. There are several ways to provide deficit irrigation for a specified CSR unit in an irrigation scheme. An optimal way has to be selected by considering all CSR units, water availability and characteristics of command area of irrigation scheme together [6]. Hence optimal allocation of water requires estimates of the outputs obtained from several possible strategies that are based on different combinations of deficit (percentage moisture stress in the soil root zone on the day of irrigation) over all the irrigation periods. In this phase (Phase 1) irrigation strategies are generated for each CSR unit for a specified set of irrigation intervals. This results in several irrigation strategies for each CSR unit, each with variable deficit for each irrigation. 


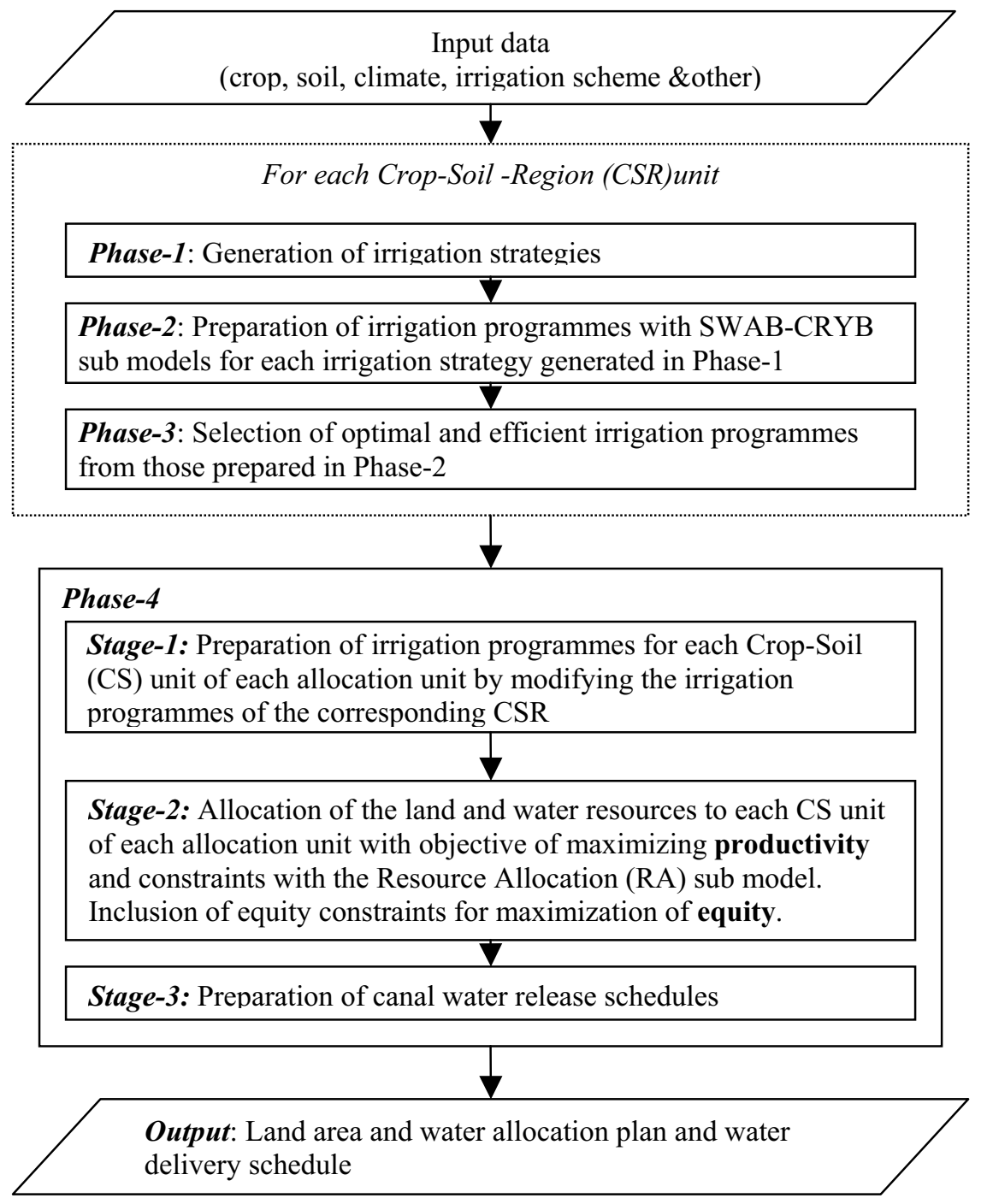

Figure 1: Area and Water Allocation (AWAM) model.

\subsubsection{Preparation of irrigation programme}

In this phase an irrigation programme that consists of information on yield/benefits and irrigation requirement (depth) per irrigation is prepared for each irrigation strategy of each CSR unit for a specified set of irrigation intervals. The irrigation programme is prepared from the following two submodels which are described later, and more details can be found elsewhere [1,2].

SWAB: In response to deficit over each irrigation (specified in irrigation strategy), this sub-model simulates daily soil moisture in the soil root zone, 
estimates daily actual crop evapotranspiration, the irrigation requirement (depth) per irrigation and the other related parameters.

CRYB: This sub-model estimates crop yield from the actual evapotranspiration estimated in SWAB sub-model and computes net benefits.

\subsubsection{Selection of irrigation programmes}

Phase 2 may generate many irrigation programmes of which several may not be important. For example the irrigation programmes generated with irrigation strategies having no deficit for successive irrigations may simulate maximum yield but with excessive irrigation water requirement. Moreover some of these programmes may not be optimal and incorporation of all these programmes in the optimization model may also make the problem computationally infeasible to solve. Therefore the number of irrigation programmes for the given unit is restricted by selecting only optimal irrigation programmes. Thus the purpose of this phase (Phase-3) is to select for each CSR unit a specified number of irrigation programmes, which are both optimal and efficient according to specified criteria.

\subsubsection{Optimum allocation of resources}

This phase (Phase-4) of the model allocates land and water resources optimally to different crops cultivated on different soils in different allocation units. It utilizes the selected irrigation programmes generated in Phase 3 .

The entire irrigation scheme is physically divided into a number of smaller units called "Allocation Units" (AU) over which land and water resources are allocated. These units may include different soils and crops however the climate is assumed to be uniform over a particular AU. The need to divide the irrigation scheme into several AUs arises from the heterogeneous nature and large extent of the irrigation scheme. By dividing the scheme in this way it is possible to make allocation of resources, water delivery schedules and management of the irrigation scheme efficient. The largest possible size of an AU is the size of the irrigation scheme itself and the smallest size of an AU is an individual farm. The intermediate sizes are the command areas of the secondary, tertiary and quaternary canals or groups of these canals.

Phase 4 of the model allocates land and water resources optimally to CropSoil (CS) units of each AU. A CS unit is a unit with similar crop and soil properties within an AU. This phase performs the allocation in three stages.

Stage-1: In this stage of Phase-4, each CS unit of an AU is assigned with the irrigation programmes of CSR unit having the same crop, soil and climate, using the irrigation programmes for each CSR unit as selected in Phase 3. As stated earlier the CSR unit is not a physical division of the irrigation scheme and hence the distribution and conveyance efficiencies cannot be considered while working out the irrigation requirements for each irrigation of a CSR unit. The AU is the physical division of the irrigation scheme and hence these efficiencies are included at this stage by modifying the irrigation requirements of each irrigation of irrigation programmes appropriately.

Stage-2: In this stage, the resources are allocated to each CS unit of each AU with chosen objective (maximization of net benefits) and constraints (resource 
availability, physical and output requirement) with the Resource Allocation (RA) sub model (described later). The RA sub model is solved by linear programming. The decision variables are the area to be irrigated under different crops on each soil type (CS) of AU and following different irrigation scheduling underlined in irrigation programmes prepared for the corresponding CS of AU (see equation 1). Note that these irrigation programmes are prepared in Phase-2; screened in Phase- 3 and modified in Stage- 1 of Phase-4. The output of the model is thus the area to be irrigated under different crops cultivated on each soil type of AU and the corresponding irrigation programme. Thus this stage gives the optimum allocation plan.

Stage-3: In this stage, the water release schedule for the canal system for the optimum allocation plan is prepared by knowing the irrigation scheduling of the selected irrigation programme for each CS unit of AU (obtained in Stage 2 of Phase 4).

\subsection{SWAB-CRYB sub models}

The SWAB-CRYB sub models [1,2] are formulated to make the model applicable to major field crops grown in the command area of an irrigation scheme. They use the data which are generally available at the irrigation scheme and general data documented by FAO if local data are not available. The soil water balance part of this model represents the system more descriptively than used in most allocation studies. Various inflow and outflow processes and a soil water balance equation used in SWAB-CRYB model are outlined in this section.

Reference crop evapotranspiration (ET) is computed by Penman-Monteith. Crop coefficient values in daily, stage wise or equation form are used to compute maximum crop ET. The actual ET is considered a function of maximum crop ET and remaining soil water content in the root zone. If the remaining soil water content in the root zone drops below a certain threshold value, the actual ET will be less than maximum ET and a deficit in ET occurs. This threshold value depends on a factor called the depletion factor, which is a function of crop, soil and maximum ET. The actual transpiration and soil evaporation are separated by computing actual soil evaporation and subtracting it from actual ET. Actual soil evaporation is considered as the function of potential soil evaporation [7] and crop factors, allowing for various prescribed patterns of soil moisture loss by transpiration, a linear root growth model, and initial soil moisture estimates.

The soil is considered as layered, with each layer characterized by its own physical soil properties. The full application depth on the day of irrigation application is computed to bring the soil moisture in all soil layers to their field capacities, and multiplied by the deficit ratio to obtain the application depth of deficit irrigation. The soil root zone is considered as a reservoir and the day is chosen as the time period for comparing inflows and outflows. Interception and capillary rise of water are assumed to be negligible. Effective rainfall and irrigation water applied constitute inflows, and outflow parameters comprise the actual soil evaporation and transpiration and the water percolated from the soil root zone. The water added through rainfall and irrigation is assumed to be distributed instantaneously to soil layers using a piston flow approach. The 
amount of water in excess of field capacity in any layer is percolated to the next layer and the water in excess of field capacity of the last layer is deep percolation. The soil moisture of any layer is computed by subtracting the transpiration corresponding to that layer and the soil evaporation from the soil moisture of the same layer on the previous day. The irrigation depth is computed by adjusting the application depth for field application efficiency and minimum possible depth of irrigation for the crop, soil and irrigation method under consideration.

In the present model, an evapotranspiration or transpiration approach can be used to estimate the yield by fitting evapotranspiration or transpiration deficits into either an additive or multiplicative form of the crop growth model. All these forms need information on the stage wise yield response factors (Ky) which depend on the soil, location and climatic conditions for the particular crop. Net benefits are obtained by computing costs as area and yield dependent costs, area dependent costs and yield dependent costs and benefits.

\subsection{Resource Allocation (RA) sub model}

The objective of the RA sub model is to maximize the net benefits and thus in turn maximize the productivity while maximizing the equity subjected to several constraints related to availability and requirement of different resources. The objective function and constraints are briefly described below. The readers are advised to refer to previous papers $[1,2,8]$ for the detailed mathematical formulation of the RA sub model.

\subsubsection{Objective function}

The objective function proposed for the maximization of the net benefits is given below by eqn. (1).

$$
\operatorname{Max} \quad Z=\sum_{i=1}^{I} \sum_{j=1}^{J_{i}} \sum_{k=1}^{K_{j i}} \sum_{l=1}^{L_{k j i}} B_{i j k l} A_{i j k l}
$$

where $i=$ index for AU, $j=$ index for soil group in allocation unit, $k=$ index for crop in soil group ( $j^{\text {th }}$ soil group of $i^{\text {th }}$ allocation unit), $l=$ index for irrigation programme for crop ( $k^{\text {th }}$ crop in $j^{\text {th }}$ soil group of $i^{\text {th }}$ allocation unit), $I=$ total number of allocation units, $J=$ total number of soil groups in $i^{\text {th }}$ allocation unit, $K$ $=$ total number of crops in $j^{\text {th }}$ soil group of $i^{\text {th }}$ allocation unit, $L=$ total number of irrigation programmes of $k^{\text {th }}$ crop in $j^{\text {th }}$ soil group of $i^{\text {th }}$ allocation unit, $Z=$ the value of objective function (currency unit), $B=$ net benefits obtained from $k^{\text {th }}$ crop irrigated with $l^{\text {th }}$ irrigation programme on $j^{\text {th }}$ soil of $i^{\text {th }}$ allocation unit (currency unit/ha), $A=$ Area to be allocated to $k^{\text {th }}$ crop irrigated with $l^{\text {th }}$ irrigation programme on $j^{\text {th }}$ soil of $i^{\text {th }}$ allocation unit (ha).

\subsubsection{Constraints}

Physical constraints: Area constraints, Canal capacity constraints, Outlet capacity constraints 
Resource availability constraints: Intraseasonal water supply constraints, Reservoir storage constraint, Availability and allocation of other resources

Output requirement constraints: Crop constraints, Food requirements constraints.

These constraints have been described in detail elsewhere [1,2]. In addition the model presented in this paper includes Equity constraints derived as follows.

Previous studies attempt to maximize the equity in area allocation [e.g. 9] or water allocation [e.g. 10]. The final objective of the allocation may be to achieve equity in distribution of output from the irrigation scheme. In these models, which consider only land allocation and assume the scheme is homogeneous, the particular depth of water diverted from the headworks for irrigating a certain crop results in the same output everywhere. In this case equity in area allocation and water distribution are the same and result in fair distribution of output. But when the heterogeneity in soil, climate and losses is also considered, the equity in area allocation and water distribution produce differing results and the output distribution among various users may not be fair. Therefore the consideration of equity in distribution of output (crop production and net benefits) is also important. Thus the following four means of achieving equity are incorporated in the model through the equity related constraints, and these are considered in turn below.
1) Crop Area
2) Water
3) Crop production
4) Net benefits

It is also important to include in the allocation process the base on which equity should be achieved along with the means of achieving equity. All the previously described models tried to achieve equity in distribution of crop area or water or output produced proportional to the land holding. However there are several arguments over the base of equity. These are discussed in detail elsewhere [6,8]. In this model, therefore, the base for equity in the allocation process is included through 'desired allocation proportion' which indicates the proportion of resources to be allocated to, or the outputs to be ensured for, a specified allocation unit out of the total resources available or total estimated outputs. The desired allocation proportion for the specified allocation unit is the ratio of the value of the base for the specified allocation unit, to which equity should be proportional, and the total value of the base for the whole scheme.

Equity in crop area: By this means, the crop area is allocated for irrigation to the different allocation units as per the given value of desired allocation proportion for equity for different allocation units

Equity in water: By this means the water is distributed to different allocation units as per the value of desired allocation proportion for equity. An irrigation manager may choose to distribute water by considering conveyance and distribution losses, or by considering conveyance losses only, or without considering any of these losses. Accordingly water can be distributed to different AUs. The allocation of water is not only a spatial issue but also temporal. Therefore the developed model considers both seasonal/annual and intraseasonal/irrigation-wise equity in water allocation. 
Equity in crop production: By this means the resources are allocated in a way to obtain the crop production to different users as per the proportion.

Equity in net benefits: In multicrop situation crop production cannot be used as output, as yields obtained from different crops are not comparable. Therefore equity in net benefits need to be considered. Thus in this case the expected net benefits obtained from irrigating the land are distributed as per the proportion for equity.

\section{Application}

\subsection{Case study irrigation scheme}

The applicability of the AWAM model to obtain the land area and water allocation plans is demonstrated with the help of case study on the "Nazare Medium Irrigation Scheme" in a semi-arid region of Maharashtra State of India. This irrigation scheme is representative of storage reservoir irrigation schemes that operate under rotational water supply in south Asia.

There are three distinct crop seasons: winter (Rabi) $\left(15^{\text {th }}\right.$ October to $14^{\text {th }}$ February), summer $\left(15^{\text {th }}\right.$ February to $14^{\text {th }}$ June) and rainy (Kharif) $\left(16^{\text {th }}\right.$ June to $14^{\text {th }}$ October). Most of the rainfall is received in the Kharif (monsoon) season. Therefore in this study, the irrigation season was considered to spread over Rabi and summer crop seasons only. Normally the irrigation interval in Rabi season is 21 days and in summer season is 14 days.

The cultural command area (CCA) of the irrigation scheme is 3539 ha. The irrigation system comprises a reservoir, a main canal $(3.05 \mathrm{~km} \mathrm{long})$, one distributory canal (11.75 km long) and four minors. There are 28 direct outlets (4 on the main canal and 24 on the distributory canal) and four minors (all on distributory canal) with 9 outlets. The CCA of all 28 outlets and 4 minors were considered as allocation units, resulting in 32 AUs [1].

The command area is characterized with four different types of soils. Based on the previous trend in the irrigation scheme, a fixed cropping distribution was assumed of -gram- $25 \%$, sorghum- $20 \%$, onion- $10 \%$ and wheat- $15 \%$ in Rabi and Sunflower $-10 \%$ and groundnut- $20 \%$ in summer season. This fixed cropping distribution was considered for investigating the issues under consideration in this paper, though the AWAM model can also consider the free cropping distribution in which the model is free to select any crops depending on which crops produce maximum total net benefits from the irrigation scheme $[1,2]$.

\subsection{Results}

The allocation plans and water delivery schedules were obtained for seven sets of irrigation interval. These were: 14 days (I-14); 21 days (I-21); 28 Days (I-28); 35 days (I-35) \{both Rabi and summer seasons\}; 21 in Rabi and 14 in summer (I21-14); 28 in Rabi and 21 in summer (I-28-21); and 35 in Rabi and 21 in summer (I-35-21). These were obtained for two scenarios; one did not include equity (no 
equity) and other included equity in distribution of water over the entire season proportional to the total cultivable area of the AU (with equity). The productivity values associated with the allocation plans for the two scenarios and seven sets of irrigation interval are presented in fig. 2.

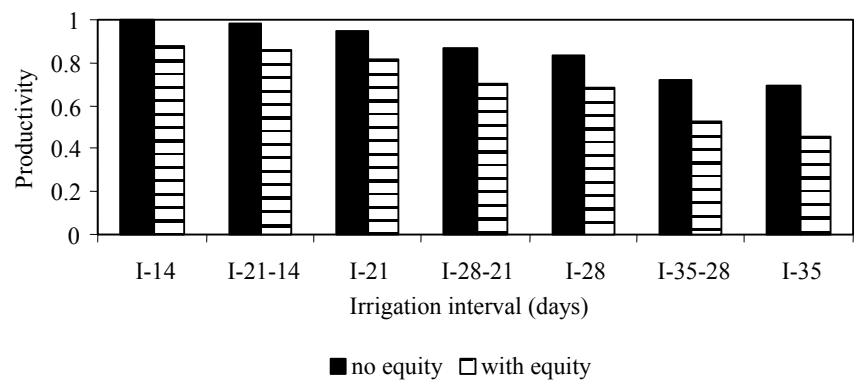

Figure 2: Productivity for 'no equity' and 'with equity' scenarios for different irrigation intervals for Nazare Medium Irrigation Scheme, India.

Productivity is quantified as the ratio of the output (measured as net benefits in monetary units) to the maximum output attainable from the resources available (land and water). The maximum net benefit Bmax, was obtained for the irrigation interval of 14 days under the "no equity" scenario. Hence the productivity values for different scenarios and irrigation intervals were computed with reference to Bmax by considering this value as the maximum attainable. Equity is related to the distribution of water to different allocation units based on cultivable command area (CCA) and can be quantified by allocation ratios of different AUs $[1,6]$. The allocation ratio for a specified AU is the ratio of actual allocation proportion as a result of allocation of water to desired allocation proportion for this AU. The interquartile allocation ratio (IQAR) is used as the measure of equity. IQAR is defined as "the average allocation ratio of the poorest quarter divided by the average allocation ratio of the best quarter" $[1,6]$.

Fig. 2 shows that the productivity values decrease with the irrigation interval for both scenarios. As expected the equity is 1.0 for the scenario of 'with equity'. However it should be noted that for the 'no equity' that do not include equity constraint, the resulting equity is zero. This indicates that the resources are getting allocated to only highly productive allocation units (with no concern for equity). For Nazare Irrigation Scheme under study, where in the objective is to achieve maximum equity with the productivity, the allocation plan for the scenario of maximum equity would be useful. The details of this allocation plan are presented in Table 1. 
Table 1: $\quad$ Land area and water allocation plan by proposed methodology.

\begin{tabular}{|c|c|c|c|c|c|c|c|}
\hline AU & $\begin{array}{l}\text { CCA } \\
\text { of AU } \\
\text { (ha) }\end{array}$ & $\begin{array}{c}\text { Allocated } \\
\text { area (ha) }\end{array}$ & $\begin{array}{c}\text { Water } \\
\text { (ha-m) }\end{array}$ & AU & $\begin{array}{l}\text { CCA } \\
\text { of AU } \\
\text { (ha) }\end{array}$ & $\begin{array}{c}\text { Allocated } \\
\text { area (ha) }\end{array}$ & $\begin{array}{c}\text { Water } \\
\text { (ha-m) }\end{array}$ \\
\hline 1 & 39 & 18.55 & 8.04 & 17 & 145 & 61.36 & 29.87 \\
\hline 2 & 36 & 15.59 & 7.42 & 18 & 147 & 62.20 & 30.29 \\
\hline 3 & 8 & 3.47 & 1.65 & 19 & 118 & 51.25 & 24.31 \\
\hline 4 & 27 & 11.73 & 5.56 & 20 & 661 & 223.76 & 136.19 \\
\hline 5 & 395 & 146.38 & 81.38 & 21 & 65 & 28.14 & 13.39 \\
\hline 6 & 33 & 14.29 & 6.80 & 22 & 156 & 67.54 & 32.14 \\
\hline 7 & 59 & 25.62 & 12.16 & 23 & 30 & 12.69 & 6.18 \\
\hline 8 & 22 & 9.55 & 4.53 & 24 & 37 & 15.66 & 7.62 \\
\hline 9 & 211 & 73.31 & 43.47 & 25 & 89 & 37.66 & 18.34 \\
\hline 10 & 68 & 29.53 & 14.01 & 26 & 93 & 39.35 & 19.16 \\
\hline 11 & 62 & 26.93 & 12.77 & 27 & 115 & 48.66 & 23.69 \\
\hline 12 & 142 & 49.24 & 29.26 & 28 & 30 & 12.69 & 6.18 \\
\hline 13 & 127 & 55.15 & 26.17 & 29 & 32 & 13.54 & 6.59 \\
\hline 14 & 81 & 35.18 & 16.69 & 30 & 87 & 36.81 & 17.92 \\
\hline 15 & 217 & 94.24 & 44.71 & 31 & 35 & 14.81 & 7.21 \\
\hline 16 & 82 & 37.99 & 16.89 & 32 & 90 & 38.08 & 18.54 \\
\hline
\end{tabular}

\section{Conclusions}

This paper highlighted the importance of considering both productivity and equity while developing the allocation plans and water delivery schedules for an irrigation scheme with limited water supply and presented the approach to develop the allocation plans and the water delivery schedules for optimization of productivity and equity. This enables the irrigation authorities to select the appropriate allocation plans depending on the local situation. The results of the model obtained with one case study on an irrigation scheme in central India indicated that the productivity and equity conflict with each other, if the water resources are allocated optimally.

\section{References}

[1] Gorantiwar, S. D., A model for planning and operation of heterogeneous irrigation schemes in semi-arid regions under rotational water supply, A $\mathrm{Ph}$. D. Thesis, Loughborough University of Technology, Loughborough, Leicestershire, UK, 1995.

[2] Smout, I.K. \& Gorantiwar, S.D., A Multilevel Approach for Optimizing Land and Water Resources and Irrigation Deliveries for Tertiary Units in Large Irrigation Schemes: 1.Method. Journal of Irrigation and Drainage Engineering, ASCE, 131(3), pp. 254-263, 2005. 
[3] Matanga, G. B. \& Marino, M. A., Irrigation Planning 1. Cropping Pattern. Water Resources Research, 15(3), pp. 672-678, 1979.

[4] Bernardo, D. J., Whittlesey, N. K., Saxton, K. E. \& Bassett, D. L, Irrigation optimization under limited water supply. Trans. ASAE, 31(3), pp. 712-719, 1988.

[5] Paul, S., Panda, S.N. \& Nagesh Kumar, D., Optimal irrigation allocation: A multilevel approach." Journal of Irrigation and Drainage Engineering, ASCE, 126(3), pp. 149-156, 2000.

[6] Gorantiwar, S.D. \& Smout, I. K., Performance assessment of irrigation water management of heterogeneous irrigation schemes: 1. A framework for evaluation. Irrigation and Drainage Systems, 19, pp. 1-36, 2005.

[7] Arora, V. K., Prihar, S. S. \& Gajri, P. R., Synthesis of a simplified water use simulation model for predicting wheat yields. Water Resources Research, 23(5), pp. 903-910, 1987.

[8] Gorantiwar, S.D., I. K. Smout \& K. Vairavamoorthy. Performance based optimization of land and water resources within irrigation schemes: 1 . Method. Journal of Irrigation and Drainage Engineering, ASCE, 132(4), pp. in print, 2006.

[9] Sampath, R.K., Equity measures for irrigation performance evaluation. Water International, 13, pp. 25-32, 1988.

[10] Burton, M.A., A Simulation Approach to Irrigation Water Management. Ph.D. Thesis, Department of Civil and Environmental Engineering, University of Southampton, Southampton, UK, 1992. 